\title{
A THEORY REGARDING THE HYPOTHETIC EXISTENCE OF AN INDIVI- VIDUAL RHYTHM IN THE ENERGETIC EXPANSION OF THINKING, FEELING AND ACTING(1)
}

\author{
Stan M. POPESCU \\ University Del Salvador, Buenos Aires
}

\begin{abstract}
Already in other opportunities ${ }^{(2)}$ we remarked the overwhelming necessity of granting more importance to the invisible part of the human being. The psychical part cannot be defended by the dynamic of colors or with air conditioners, functional desks and music, training classes, spectacles, boots and security gloves, cheap dining-rooms, etc., because it is subject to all the perils of the not visible factors and elements. The century of automatism together with "physical comfort" has to worry about psychical and spiritual comfort. Otherwise our society within two or three decades, when it performs the balance sheet of scientifical achievements, will find out bitterly the existence of a dramatic deficit. Automation will continue its way in triumph impeled by robots and by mental and neurotic patients.

Oriented by these preoccupations we have opened the doors of our Department of Industrial Psychology (that existed in an important metallurgical enterprise of the Argentine Republic) to all the men and women that suffer due to the different factors that have arisen out of work. Certainly our task was not limited only to the restoration of people's moral and psychical health ${ }^{(3)}$ and so, attention in this sense did not overpass the number of 261 men and women (between workmen, employees, technicians and supervisors). Notwithstanding this, we got to establish certain facts that created a valuable material for an investigation cencerning "the source of uneasiness in the workman," the summary and conclusions of which we present here on.
\end{abstract}

\section{The Common Source of Manufacturing Uneasiness}

Out of the 261 people that were attended to, 219 could be classified in the following classes:

A. UNEASINESS DUE TO CONGENITAL DESEASES:

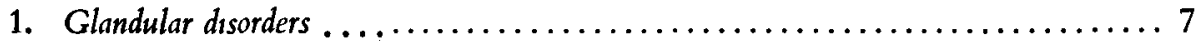

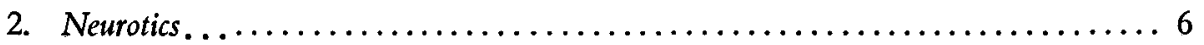

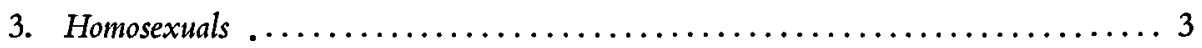

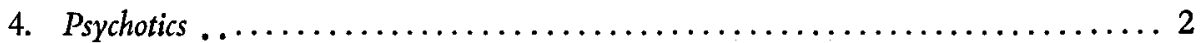

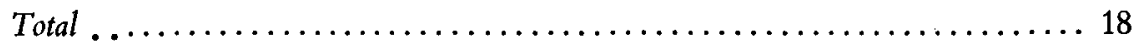

B. UNEASINESS DUE TO SITUATIONS NOT CONCERNING WORK:

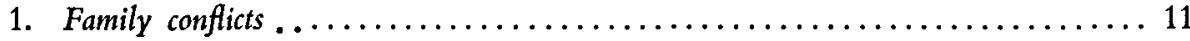

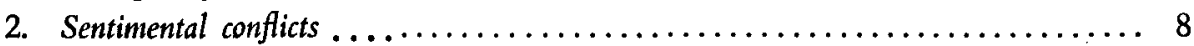

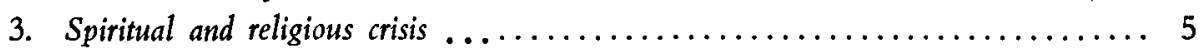

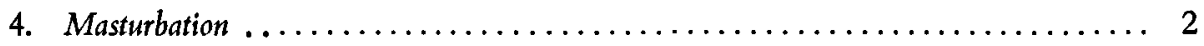


5. Beginning of inversion due to unfavorable surroundings ................. 1

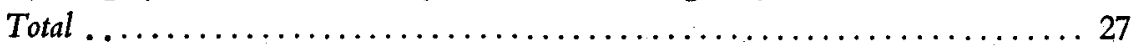

C. UNEASINESS CAUSED BY WORK PROBLEMS:

1. Inadequate social behavior of the supervisors . ..................... 44

Nearly all the people suffered depressions-in some cases they became acute-due to the inconsiderate behavior of the supervisors and overseers. It is interesting to remark that the men as well as the women did not arrive hardly ever to express clearly the motives that they believed constituted the source of tensions, unwillingness, excessive acuteness in their sensibility, etc. Only through the sessions could we realize that the causes of uneasiness were the superiors' behavior that lacked of tact and human sense. Another curious thing that comes from the investigation of this group is that the 44 members were selected from the areas where the supervisors lacked the necessary preparation for leadership. In some cases it could be observed that precisely the supervisor, that had attended to the classes of Human Relations (there were two out of the six that we refer to), gave evidence of less tact in their behavior towards their inferiors. The explanation is simple: they thought that training in human relations was fit to transmit this spirit to the direct supervisors and not be practiced by themselves directly. A greater part of the individuals were of the emotive type, outstanding in a certain supersensibility. Some had arrived to disturb the working group due to their frequent emotional outbursts. Others had contaminated the family surroundings arriving to situations of conflict in the home.

2. Uneasiness at not being able to perform the functional sphere of the task ...... 39

Some had got to perform tasks that were superior to their capacity owing to the policy of the company (that consisted in promoting the oldest elements within the same area of work). A low I.Q. (eight individuals hardly reached an I.Q. of 87) as well as the lack of adequate instruction were the cause of a general psycho-mental mobilisation with the purpose of facing the requirements of the task. The individual tried to compensate their insufficiency by means of readings, evening classes, etc., or they spent their energy in supplementary hours. There were some that limited themselves to comply what was strictly necessary, but they disguised their anguish and fears by a self-sufficient behavior. Two individuals had even taken home some tasks so solution them during the week end without letting their superiors knowing and without asking the correspondent payment for the hours worked at home. Some of the tasks required to be managed by people with a level of intelligence superior to 105 and with a complete secondary instruction. The people that performed them had a low intelligence level and elementary instruction. At last, physical weariness, a permanent state of anxiety, anguish and fear of loosing the job, conveyed to

1. The present article appeared in the review "Industrial Psychology" No. 9, 1962, December, Buenos Aires, Rivadavia 717, floor 7, Argentino.

2. In our article "Moral health of the workman", we remarked: "If the modern society wants to resolve the problem of social equilibrium it must look for a new method of approaching the working level. Approximation is not only achieved by the privileged class trying to come down a few steps, but when it does all that is possible to lift up the workman's moral and to strengthen his spirit...."(Social Dynamic, August, 1955)

3. See our article published in "International Engineering Industry" by McGraw-Hill, New York, U.S.A., No. 3, 4, 5, and 7, 1961. 
a general uneasiness with symptoms that evidenced the beginning of neurosis.

3. Uneasiness at the non-identification with the general policy of the company ..... 26

The 26 employees and workmen had fallen into a state of tension and resentment against what they called "a bad policy of the company." They suffered from hallucinations and they went through states of extreme irritability that disturbed the familiar and social surroundings.

4. Uneasiness at the non identification with the task

Due to the frustration of their vocations, the individuals performed their tasks with evident disgust. As years went on bitterness and the lack of satisfaction created for them a complex of uselessness in life. The symtoms were: depressions, apathy, aggressive attitudes in unexpected moments, etc.

5. Uneasiness due to the superior capacity with reference to the functional sphere

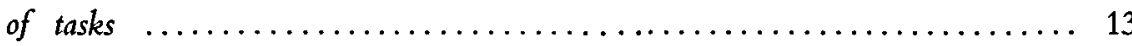

For different reasons (some had accepted the job with the intention of keeping it for a short time, others with the promise of progressing quickly or getting ahead in their tasks etc.) the employees and workmen (among them there were 4 supervisors) of this class that had remained during long years performing simple tasks. All of them were trained (they had at least gone through 4 years of the secondary school) and the I.Q. oscillated between 100 and 108. The tasks were performed as a routine. After going through a period of conformism and skepticism they arrived to a state of lethargy and abulia.

6. Uneasiness due to the uniformity and automatism of movements $\ldots \ldots \ldots \ldots \ldots 8$

There were 5 workmen and 3 employees that performed very automatic tasks. They evidenced permanent weariness, bad humor, indifference towards the things that before were for them a motive of amusement and ease, untidyness in their way of dressing, headaches, etc.

7. Uneasiness due to conflicts orginated by competitive situations and rivalry with

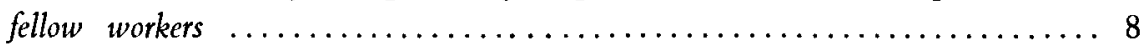

They had arrived to a state of hypersensibility, inflation of the ego, excessive irritability, etc.

8. Uneasiness due to a difficult economical situation $\ldots \ldots \ldots \ldots \ldots \ldots \ldots \ldots$

They lived in permanent tension, they suffered from lapsus of memory, of incapacity in arriving to conclusion in complicated reasoning, dreads and depressions.

9. Uneasiness due to inadequation to the work environment $\ldots \ldots \ldots \ldots \ldots \ldots . \ldots 2$

There were two country men from septentrional provinces that had came up to the Capital with the purpose of working so as to help their relations that were ill. They complained of the noise of machines, of the heary jokes played on them by fellow-workers, of the crowd of people around them, etc. They felt tired, bared, unsociable and they kept up an attitude of mistrust and a lack of sociability. Their superiors complained, with reference to them of certain inconstancy in the performance of their work.

THE 42 OTHER CASES AND A THEORY REGARDING THE HYPOTHETIC EXISTENCE OF AN INDIVIDUAL RHYTHM IN THE ENERGETIC EXPANSION OF THINKING, FEELING AND ACTING. 
During 8 years of investigation and acting in the Psychology Department, our attention was drew by the existence of some people (as years went on we had occasion of close by analyzing the cases) that could not be classified in the already mentioned ranks, neither could we find other motives of uneasiness (traumas during infancy, adolescence or early youth). Therefore we concluded that there existed an individual rhythm in the energetic expansion of thinking, feeling and acting that due to its oscillatory fluctuancy differed from the rhythm of the organized group, from that of other individuals or from the family one. This fact provoked a chronic uneasiness evidenced by a state of anxiety and displeasure with themselves.

Out of the 42 cases we have chosen the most representative and suggestive ones, that allow us to formulate the theory. Notwithstanding, before presenting the three cases, we must remark: a) All the individuals (42) were investigated and submited to the following battery of tests: a test of structural intelligence ${ }^{(4)}$ of total intelligence ${ }^{(5)}$ of auditive memory ${ }^{(6)}$ of visual memory(7) the test of the landscape ${ }^{(8)}$ attention $^{(9)}$ Rorschach, Tu Anima and the periods of reaction were taken with the Beck apparatus on the last 23 individuals. b) All the subjects had a I.Q. that oscillated between 91 and 126. The examination of aptitudes gave a result that oscillated between average and superior to average in a more or less degree. c) The great majority proved normal or within normality concerning temperament and character. d) The reactions obtained with the Beck apparatus showed normality in the 23 cases. e) The interviews were performed within a climate of absolute good will in what concerns the subjects. All of them presented spontaneously and cooperated with interest. f) In all cases the immediate superiors, some fellow-workers and relations were also interviewed.

\section{THE FIRST EXAMPLE: INDIVIDUAL RHYTHM IN THE ENERGETIC EXPANSION OF THOUGHT.}

Mr. YY is 34 years old. He stidied in an Technical School and graduated as a mechanic technician. He entered as a draftsman in a mechanic factory when he was 23 years old and he continued there until he was 25 . During the last seven years he worked as a designer in one of the plants of the Company where the Psychological Department functioned.

He presented himself revealing uneasiness, anxiety and a general indisposition without specifying the symptoms: "I could not say that my head aches me, nor that I cannot sleep. I do not feel well. That is all" he expressed the first day. He had had a happy infancy. His adolescence was a normal period in his life without economical preoccupations. The parents lived happily. He had an elder brother and a younger sister. He was married and he had two small children. His wife was "very kind, comprehensive and she helps me in

\footnotetext{
4. It is Amthauer's structural test, simplified and combined by the author with four other tests. It was standardized due to 3.000 examinations in the Argentine Republic.

5. It is a test elaborated by the author in the Argentine Republic. It was standardized on the basis of more than 3.000 adults, 1.000 adolescents and 200 children from the primary schools.

6. We have presented this test in the No. 3 review "Industrial Psychology".

7. It consists in 20 drawings that the subject must remember, writing after seeing all of them.

8. The subject must draw a house, two trees, and some other details.

9. It is a simplified test, similar to the Toulouse.
} 
everything" he said. "I married in love and I continue so as the first day of my wedding." He was happy with the salary, with his work and with his companions. The supervisor "was very good." He ate and slept sufficiently. On weekends he used to go with his family to the country where he had a cottage. He had a great deal of books of his speciality, novels, magazines and newspapers. He attended theaters and musical shows. "What preoccupies me is the fact that sometimes I do not produce as I should like to. I do not know what is the matter with me. The same thing was observed by my supervisor and my companions." The supervisor's opinion: "In fact I am surprised that he has presented himself as having psychical problems. He is an intelligent draftsman, punctual and responsible. A good companion and with great equilibrium in every thing. It is true that he goes through periods of slowing down but he compensates them with others or great activity. Very frequently he solves problems that very few are able to deal with. I even dare say he solves them even with the same facility as an engineer does." The opinion of a fellow workman: "He is the best of all of us. He is witty. Sometimes he works very slowly but always well. When he is in one of these periods we do not think ill or him as all of us work slowly due to the kind of tasks we perform. But when he works, we call on him, he solves many problems just in a moment."

We have noticed that in the section a constant and uniform rhythm or work was kept on. Most of the employees were young draftsmen with a fairly good degree or education. YY was appreciated and esteemed. All agreed with the supervisor and with the companions statement: these people were specially interviewed. YY had periods that oscillated between 10 and 15 days during which he worked like all the rest of his companions, but due to his periodical increase of capacity the lapsus of slowing down seemed queer. "Some years ago-said the supervisor-YY found a rapid solution to a problem of saving material; a few months later a similar problem came around, but $Y Y$ needed much more time to solve it although he had already had an antecedent".

To prove the supervisor and the companions statement we asked YY to solve the same tests in four different periods ${ }^{\text {an }}$.

The results were as follows:

\begin{tabular}{c|c|c}
\hline & Lienert Test & Log. Dod. Test \\
\hline 1. V First test & 23 & 6 \\
12. V Second " & 28 & 11 \\
24. V Third " & 24 & 8 \\
5. VI Fourth " & 29 & 11 \\
\hline
\end{tabular}

During to the investigation that we performed we arrived to the conclusion that YY was a completely normal individual, with an intelligence a little over the average, spatial imagination superior to normal, good memory, good attention, normal psychomotor reactions, normal associative power, healthy attitudes and a correct behavior. His uneasiness was due to the existence of a peculiar personal rhythm in the expansion of mental energy.

10. It is Lienert's technical-mechanical test of intelligence and another of Logical Deduction (space orientation) ellaborated by the author of these lines. 
It seemed as if his mental energy was subdued to an inferior strength that expelled it sometimes with greater intensity and others with loss. This phenomenon could be compared to that of the sistole and diastole, that distributes and contracts - respectively - the blood in the human body.

\section{THE SECOND EXAMPLE: INDIVIDUAL RHYTHM}

IN THE ENERGETIC EXPANSION OF FEELING

Mr. XX is 29 years old. He is an engineer and he fulfills the post or supervisor in a section of the Technical Direction. He is married and he has a son. He lives with his parents and his family in a big house. He had a normal infancy and adolescence. His parents gave him an adequate education, and he was brought up in a comfortable environment, together with his three younger brothers. He graduated as an engineer when he was 25 years old (when he married) and he entered the company in that same year. During his four years of work he was remarkable for his capacity and dedication, lately he was appointed as section supervisor.

When he presented himself to our Department, he said: "I am healthy. I sleep and eat well. I feel very happy with my wife and son. I got on very well with my parents. I feel very comfortable with my work but there is something not going right. I feel queer. As a fact I always feel uneasy when I compared myself with my colleagues or with other people. I am preoccupied about this situation. My wife told me that in certain opportunities. I haven't a uniform behavior with her. The affair would not have troubled me if I hadn't noticed it by myself. Some days ago, one of my employees gave me to understand something similar. Is it because I am too preoccupied about myself? Is it selfishness or narcissism? What is the matter with me: I would like to live and work in peace, without this uncomfortable feeling of my strange situation."

One of the technicians of the section said: "XX is an excellent engineer, supervisor and companion. What $I$ have observed queer in him are the same what frequent changes in his behavior towards us. Sometimes in the morning he is silent and serious. Always correc and polite but reserved. In the afternoon I observed that he is much more friendly. .... Sometimes even affectionate. But even so, we are lucky with him. He is educated, comprehensive, capable and just."

An employee of the same section stated: "He is a real supervisor. We cannot ask more. He knows how to direct and we are very fond of him. One would think that sometimes he is shut up within himself. But afterwards he is friendly and sociable."

XX's father gives his opinion: "He was always correct and hardworking like his brothers. What I noticed yes from his infancy were certain changes in his attitude. He past from a moment of meditation or reflection to a more open and affectionate one. Generally during the morning he was more taciturn and during the afternoon more expansive."

XX's wife said: "I am very happy with him. He is kind, comprehensive, intelligent and he possess self control. My father in law is right in what he says about my husband's changes of modality. Many times I have noticed during the holidays, and even during our honey moon, that he is more reserved during the morning and more affectionate in the afternoon. He himself told me that he could not explain the reason of this behavior. It 
is to remarked that XX was appreciated by his superiors and that they considered him as one of the best professionals. In his output he seemed very uniform and the works he performed were good.

During an informal interview with XX's wife (the interviews with the subjects relations took place at the psychologists house) said that at first she had suffered, but that as she realized that his attitude did not become unsociable or rough, she considered that the affair was not important.

Being in the same conditions of normality (the tests upon abilities and capacity as well as the projective ones showed a normal personality) as YY, XX acted and solved the problems of his task easily, but he evidenced a cyclical fluctuation in the energetic expansion of feeling.

\section{THIRD EXAMPLE: INDIVIDUAL RHYTHM IN THE ENERGETIC EXPANSION OF ACTING}

Mr. ZZ is 28 years old. He is a workman and he works in the swing-bar of a section where sometimes the tasks are performed by turn among the different workman. He has went through the six primary courses and he assisted to evening classes concerning one speciality of radio technician. He is married and he has two daughters. He lives with his family in a small emergency house. According to what he said, he had a happy infancy. As his father perceived a good salary and his mother contributes to keep up the home working in a sweater factory. When he finished his military training ZZ entered an establishment as a day laborer. Shortly afterwards he got to manage the swing-bars and cuthers.

He presented himself saying that he wanted "to progress." "I observe that I have periods during which I do not fulfilly my task as usual. During the hours of work when I am all right I take out 600 pieces, but sometimes my output decreases. I feel angry with myself. Some days I cannot take out more than 450 pieces and what is very queer is that I feel well, I am not ill, I eat well, I sleep well. With my wife I get on perfectly well and we love each other. What must be the matter?

The supervisor said: "He works consciously. He is one of the best." When he was asked about the number of pieces he added: "Sometimes he slacks down a little, but he works well. He has had moments like everybody, or preoccupations. But he is always in good humour and he is a good companion. He is obbedient and orderly."

A fellow worker's opinion: " $\mathrm{ZZ}$ is an excellent friend all of us. He always has a joke and a smile. He does not worry about misfortunes. It is true that sometimes he complains because he thinks that something queer is happening to him and he cannot reach the quantity of pieces he wants to. But taking out 450 is sufficient. Maybe he gets tired."

After explaining him the purpose we asked him to summit himself to two tests of hand dexterity, just during the periods when he observed a decrease in his output, repeating the tests during the time that he considered "normal."

Like in the other two examples, $\mathrm{ZZ}$ was a normal person from the intellective point of view, temperamental (a little more emotive than the others) and characterological. The psychomotor reactions showed normality. His behavior is excellent both in the plant and at home. A neighbor gave us the wife's impression: "I am very happy with him 
because he is kind and hardworking. He is very fond of his daughters."

The results were as follows:

\begin{tabular}{l|c|c|c}
\hline & To dismount: & To mount: & Hand synchronization \\
\hline 7. XI First test & $3,15^{\prime \prime}$ & $4,03^{\prime \prime}$ & $60^{\prime \prime}$ \\
29. XI Second test & $2,06^{\prime \prime}$ & $2,45^{\prime \prime}$ & $48^{\prime \prime}$ \\
28. XII Third test & $3,08^{\prime \prime}$ & $3,52^{\prime \prime}$ & $58^{\prime \prime}$ \\
15. II Forth test & $1,55^{\prime \prime}$ & $2,34^{\prime \prime}$ & $46^{\prime \prime}$ \\
\hline
\end{tabular}

\section{CONCLUSIONS}

Careful analysis performed with the 42 subjects and very specially with $Y Y, X X$ and $\mathrm{ZZ}$ allowed us to conclude about the existence of a new factor that contributes to clarify certain behavior of the workman. This behavior seems to disturb the person due to the lack of a logical explanation of his strange states. We think that there exists a regular phenomenon of the energetic expansion that acts independent from will, from different mental situations, from external contingency, fatigue, inconveniences, etc. This pehnomenon is cyclical and appears alternatively, sometimes by means of an effervescency or energetic increase. During this period the individual thinks, feels and acts normally or more than other times there is a decrease or lack of effervescency and the individual thinks, feels and acts less intensively. Therefore there would be a cyclical rhythm of energetic dilatation and retraction that acts on certains human beings with reference to the mind (thinking), to the affective part (feeling) and to the dynamic one (acting or operating).

We ask ourselves of certain feelings of guilt and other alike psychical alterations are not caused by the facility with which the individuals during the periods of energetic retraction accept suggestions, influences or ideas, which being established in the person emerge contradictorily with the proper ideas issued during the periods of intellectual energetic increase. In this way we could explain certain antagonic behaviors in normal individuals when they are in a situation of "populace-mass", when they let themselves be dragged easily by the emotional fluid of the crowd, behaving as populace-mass and no like a human being.

Certainly the investigation that has been performed does not offer yet sufficient elements so as to back our theory. Neither we dare formulate a supposition regarding the energy that causes decrease or increase of mental, affective and dynamic energy in the individual; notwithstanding we think the following comparison exact: if human body lives due to the movements of systole and diastole, energetic strength could be distributed in the daily activity also by means of a phenomenon of periodical dilatation and retraction with the purpose of keeping an equilibrium in the development of the sprit. This equilibrium would be affected when the individual moves within a group whose members possess very different individual rhythms. In organized groups, it is the formal leader that imposes a rhythm of work and a style of acting but at last he is obliged to accept the general rhythm that issues from the confluence of the individual rhythmes. If one of the members possess a rhythm of energetic expansion that is to fast, there becomes an alteration and the spritual equilibrium of the different member is in danger. In his private life something alike takes place: if the individual has an energetic expansion very different to that of the person with whom he lives, 
a situation of conflict arises. This can provoke psychical alterations in the family group.

Up to the present applied psychology has dealt with instincts, tendencies, emotions, perceptions, memory, temperament, character, trying to measure, to explain, and to find laws of their interactions. We ask if the theory about an hypothetical existence of a cyclical rhythm of the energetic expansion based on our investigation, could not contribute to explain certain alterations in the behavior of the man that works intellectual or physically. Maybe it could illuminate certain other doubtful points in the intricated process of man's psychical activity.

\section{SUMMARY}

On investigating the reasons of uneasiness of the man who works, the author divides a group of 261 persons who spontaneously reported to the Industrial Psychology Department, in two categories: the former pertains to individuals whose disturbances are covered under the already known phenomena. The latter one (42 persons) assumes to comprehend disturbances caused by a cyclical rhythm of energetic expnisaon. This individual rhythm appears in intellectual, affective and dynamic activities of the man who works. It is similar to the diastole and systole phenomenon: the energy expands itself periodically causing a dilatation or inflation, and other times retracts causing deflation or retraction. During the latter the human being is more propense to assimilate ideas, influences and slogans preelaborated by other. During the inflation periods, motivating an energetic effervescence, the existence of ideas and influences of others could be the cause of different psychic disturbances. The individual phenomenon of energetic dilatation and retraction also explains the incongruence and discrepance which appears during work, among some individual and the rest which form the work group. 